\title{
O Delicado Manejo da Transferência em Paciente de Difícil Acesso
}

\author{
Gentle Handling of Transference in a Patient
}

Who is Difficult to Reach

El Delicado Manejo de la Transferencia en Paciente de Difícil Acceso

\section{Eduardo Name Risk \&} Manoel Antônio dos Santos

\author{
Universidade de São Paulo
}

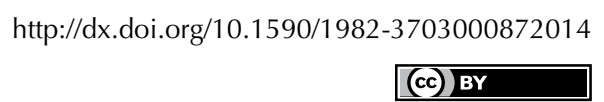


Resumo: A transferência constitui um acervo de experiências emocionais revividas pelo paciente com o analista. Em pacientes de difícil acesso, as manifestações transferenciais costumam ser intensas e imprevisíveis. Este artigo tem por objetivo analisar algumas vivências transferenciais de uma paciente de 29 anos durante seu atendimento psicoterápico em um serviço-escola de Psicologia. Utilizou-se como estratégia metodológica o estudo de caso e o enfoque psicanalítico para análise dos dados. Durante o processo terapêutico em questão, o vínculo era constantemente atacado por defesas paranoides e por manifestações de angústia, que interrompiam o fluxo associativo, por vezes recuperado mediante a continência afetiva do terapeuta. Do ponto de vista transferencial, notou-se que a permanência do contato analítico desestabilizava os padrões de pensamento e condutas defensivas da paciente, o que suscitava-lhe o sentimento de que parte de seu mundo interno estava desorganizado. Em vários momentos, a paciente sinalizou estar incomodada com as interpretações. Conclui-se que, frente à potencial desorganização do mundo interno, as possibilidades interpretativas advindas da transferência devem ser manejadas com cautela pelo psicoterapeuta, para que não intensifiquem estados primitivos de fragmentação egoica.

Palavras-chave: Transferência. Psicoterapia. Interpretação psicanalítica.

Abstract: Transference is the redirection of past emotional experiences of the patient relived in the relation with the psychotherapist. In patient who is difficult to reach, transference manifestations are usually intense and unpredictable. This study aims to analyze the transference experience of a 29-year-old woman during the course of a psychoanalytic oriented psychotherapy in an educational psychology service. A case study was used as the methodological strategy, and the psychoanalytic approach was applied to analyze the data. In therapy, the link was constantly attacked by paranoid defenses and manifestations of distress that interrupted the flow of associations, sometimes redeemed by the therapist's emotional continence. From the standpoint of transference, the permanence of analytic contact, destabilizing the thought patterns and defensive behaviors of the patient, possibly produced the feeling that part of his inner world was in disarray because in many instances, the patient seemed to bother with the interpretations. The results indicate that considering the potential disorganization of the patient's internal world, the possibilities of using transference interpretations should be handled carefully and with moderation by the psychotherapist so that it does not intensify the primitive states of ego-fragmentation.

Keywords: Transference. Psychotherapy. Psychoanalytical interpretation.

Resumen: La transferencia constituye una colección de experiencias emocionales revividas por el paciente con el terapeuta. En los pacientes de difícil acceso las manifestaciones transferenciales son generalmente intensas e impredecibles. Este artículo se propone analizar algunas vivencias transferenciales en una joven de 29 años con tratamiento psicoterápico de orientación psicoanalítica en un servicio escuela de Psicología. Fue utilizada como estrategia metodológica el estudio de caso y el enfoque psicoanalítico para analizar los datos. En la terapia, el enlace fue atacado constantemente por las defensas paranoides y las manifestaciones de angustia, que interrumpió el flujo asociativo a veces redimido por la continencia emocional del terapeuta. Desde el punto de vista de la transferencia, se observó que la permanencia del contacto analítico desestabilizaba los patrones los patrones de pensamiento y los comportamientos defensivos del paciente, produciéndole la sensación de que parte de su mundo interior estaba desorganizado. En varios momentos la paciente se mostró molesta con las interpretaciones. Se concluyó que, frente a la potencial desorganización del mundo interno de la paciente, las posibilidades interpretativas provenientes de la transferencia deben ser manejadas con cautela y parsimonia por el terapeuta, para que no se intensifiquen estados primitivos de fragmentación ecoica.

Palabras clave: Transferencia. Psicoterapia. Interpretación psicoanalítica. 


\section{Introdução}

Este artigo situa-se conceitualmente no intrincado campo da transferência e se propõe a discutir as vicissitudes transferenciais em paciente de difícil acesso. Utiliza, para tanto, o caso clínico de uma jovem atendida em psicoterapia psicanalítica no contexto de um serviço-escola de Psicologia. Com esse objetivo, apresentam-se inicialmente as formulações de Freud, Klein e Winnicott a respeito do tema, a fim de fundamentar a descrição clínica e a análise do relato de caso. $\mathrm{Na}$ apresentação do estudo de caso, discutem-se as especificidades do processo transferencial.

Desde sua formulação original por Freud, a noção de transferência recebeu contribuições de inúmeros autores que expandiram consideravelmente seus limites e aplicações. Nesse sentido, no âmbito deste estudo, sempre que utilizarmos o termo transferência estamos aludindo a um fenômeno multifacetado, complexo e polissêmico, que não pode ser tomado como um fenômeno unitário, linear e unidimensional, dadas as diversas formulações existentes nas diferentes escolas psicanalíticas. Para Laplanche e Pontalis (2001), uma definição de transferência é tarefa desafiadora, uma vez que esse construto assumiu uma multiplicidade de significados para diversos teóricos, sendo apresentada como:

O processo pelo qual os desejos inconscientes se atualizam sobre determinados objetos no quadro de um certo tipo de relação estabelecida com eles e, eminentemente, no quadro da relação analítica [...]. A transferência é classicamente reconhecida como o terreno em que se dá a problemática de um tratamento psicanalítico, pois são a sua instalação, as suas modalidades, a sua interpretação e a sua resolução que caracterizam este (Laplanche \& Pontalis, 2001, p. 514).

Ainda segundo os referidos autores, há uma lacuna no que tange à conceituação da transferência na obra de Freud, uma vez que, às concepções explícitas sobre sua definição sobrepõem-se as experiências afetivas relatadas nos casos clínicos, em que se pode notar este fenômeno em ação, tal qual intentamos relatar no presente estudo clínico. Não cabe aqui uma revisão do desenvolvimento desse conceito na obra de Freud, bastando não perder de vista que ele sofreu modificações durante seu percurso de elaboração teórico-clínica. Em Fragmentos da análise de um caso de histeria, Freud (1905/1996) discorre sobre a interrupção do tratamento por Dora, justificando-a por não ter conseguido notar os primeiros sinais da transferência, em que ele era colocado, na fantasia inconsciente, como substituto do pai da paciente. $\mathrm{O}$ autor considera que a transferência constitui um aspecto próprio da neurose que é revelada pelo tratamento psicanalítico, definindo-a como: "reedições, reproduções das moções e fantasias que, durante o avanço da análise, vêm despertar-se e tornar-se conscientes, mas com a característica (própria do gênero) de substituir uma pessoa anterior pela pessoa do médico" (p. 111).

Para Laplanche e Pontalis (2001), Freud deparou-se de modo contraditório com a função da transferência ao longo de sua obra, já que ao mesmo tempo em que essa constitui uma forma de resistência, também permite que analista e paciente revivam sensivelmente elementos de sua singularidade, ao se confrontarem com seus desejos e fantasias inconscientes.

No trabalho A dinâmica da transferência, assim como em outros escritos que tratam do tema, Freud (1912/1996a) considera que a transferência constitui uma forma de resistência, visto que, conforme a análise vai progredindo, o médico passa a investigar pontos em que a libido está fixada, procurando torná-la acessível à consciência. No entanto, nessas ocasiões, os impulsos que colaboraram para regressão da libido se manifestam sob a forma de "resistências" ao trabalho analítico, que podem irromper como associações que dizem respeito à figura do analista, cuja compreensão se dá via investigação de suas relações com a resistência. Ainda no referido artigo, o autor argumenta que os impulsos inconscientes tendem a ser recordados pelo paciente conforme "a 
atemporalidade do inconsciente e sua capacidade de alucinação" (pp. 119), devendo o analista esforçar-se para remontá-los à sua história de vida e ao âmbito do tratamento, o que se dá mediante análise dos processos transferenciais. Essa concepção inova porque coloca em evidência que, a despeito de suas dificuldades de manejo, a transferência presta grande serviço ao tornar conscientes os impulsos eróticos reprimidos, consideração reafirmada na conferência Resistência e repressão (Freud, 1916-1917/1996).

Em Esboço de Psicanálise, texto escrito por Freud (1938-1940/1978) no final de sua vida e publicado postumamente, o autor afirma que o paciente não se contenta em ver o analista como um conselheiro, um "guia numa difícil escalada de montanha". Ao contrário, concebe-o também como o retorno de alguma figura importante de seu passado ou de sua infância, transferindo para ele "sentimentos e reações que, indubitavelmente, aplicam-se a esse protótipo" (p. 221).

Essa transferência logo demonstra ser um fator de importância inimaginável, por um lado instrumento de insubstituível valor, e por outro, uma fonte de sérios perigos. A transferência é ambivalente: ela abrange atitudes positivas (de afeição), bem como atitudes negativas (hostis) para com o analista, que, via de regra, é colocado no lugar de um ou outro dos pais do paciente, de seu pai ou de sua mãe [...] uma vez que a transferência reproduz a relação do paciente com seus pais, ela assume também a ambivalência dessa relação (Freud, 1938-1940/1978, pp. 221-222).

Assim, na concepção freudiana, quando positiva, a transferência potencializa a condição do paciente de colocar-se em contato com a realidade psíquica, a qual recorre para tornar-se sadio e livre "de seus achaques", decorrendo daí o desejo de agradar o analista, de conquistar seu amor, o que motiva sua colaboração. Pelo período que dura essa "luade-mel", o paciente "desiste dos sintomas e aparenta ter-se restabelecido - por amor ao analista" (Freud, 1938-1940/1978, p. 221). Essa situação contribui também para uma espécie de "pós-educação do neurótico", segundo Freud, ou seja, estando no lugar do pai ou da mãe, o analista pode corrigir erros de responsabilidade das figuras parentais, uma vez que elas são o esteio e a origem do superego. Na delegação que o paciente faz na transferência positiva, concede ao analista o poder exercido pelo superego sobre o seu ego. Todavia, essa tarefa deve ser desempenhada respeitando-se a idiossincrasia do paciente, ou seja, o analista não pode deixar-se levar por suas próprias inclinações, sob pena de repetir o que foi realizado pelos pais, ou seja, a retirada da independência e autonomia do filho (Freud, 1938-1940/1978). De acordo com D'Avila Lourenço (2005), que realizou um estudo teórico sobre o conceito de transferência na obra de Freud, o método psicanalítico deve propiciar meios que reportem os conteúdos da neurose ao setting analítico, particularmente à figura do analista, "isso faz da cena analítica o palco privilegiado de manifestações dos conflitos intrapsíquicos do paciente" (p. 144).

Por se tratar de conceito plural, definido conforme a abordagem teórica que norteia o processo analítico, apresentamos brevemente as ideias de outros autores a respeito do tema, a fim de não apenas evidenciar a pletora conceitual e de vivências que ele abarca, como também de fundamentar as vinhetas clínicas coligidas na segunda parte deste estudo. Klein (1952/1991), que dedicou apenas um artigo ao fenômeno transferencial, aproxima-se da concepção freudiana quando define transferência como conjunto de experiências psicológicas, que são revividas na situação analítica como se fossem inéditas e não pertencentes ao passado do paciente.

Que são transferências? São novas edições ou fac-símiles dos impulsos e fantasias que são despertados e tornados conscientes durante o andamento da análise [...] sua premência em transferir suas primitivas experiências, relações de objeto e emoções é reforçada, e elas passam a localizar-se no psicanalista. Disso decorre que a paciente lida com os conflitos e ansiedades que foram reativados, recorrendo aos mesmos mecanismos e mesmas defesas, como nas situações anteriores (Klein, 1952/1991, p. 71). 
Winnicott (1993) discute como a transferência se dá em casos em que o ego do paciente não se estabeleceu plenamente, quando ainda não é "capaz de manter defesas contra a ansiedade provocada pela pulsão e de assumir a responsabilidade por elas" (p. 484), portanto, o analista tomará contato com estágios anteriores ao estabelecimento do ego. Para o autor, a transferência implica a existência de um ego capaz de erigir defesas contra a ansiedade decorrente da pulsão, assumindo-as responsivamente, ocasião em que o analista preocupar-se-á mais com o trabalho analítico do que com a manutenção do setting. Ao contrário do que ocorre com pacientes cujo ego não se estabeleceu verdadeiramente, isto é, em que o falso self protege o verdadeiro self para garantir sua continuidade, sob aparência de uma integridade ilusória. Nesses casos, o setting torna-se mais importante do que a interpretação. $\mathrm{O}$ analista deve prover um ambiente suficientemente bom que promova paulatinamente a emergência de um ego capaz de suportar as pressões do id. Ao sentir o ambiente confiável e estável, o paciente pode expressar seu self verdadeiro, "e a partir disto, pode finalmente ser feita uma análise comum das defesas do ego contra a ansiedade" (p. 487).

Fundamentando-se nas proposições de Winnicott, Safra (2005) afirma que a situação transferencial deve ser manejada pelo analista de modo semelhante ao que a mãe realiza em sua função de "apresentar objetos", ou seja, apresentando a realidade de maneira gradual e dosada à criança, conforme suas possibilidades de apreendê-la. Assim, na análise, o analista apresentaria as situações emergentes no campo transferencial conforme a possibilidade do paciente em utilizá-las para alargar as fronteiras de contato com seu mundo mental.

O paciente de difícil acesso é definido como aquele que, apesar de sua aparente cooperação e interesse no processo psicoterápico, apresenta forte resistência a entrar em contato com seus afetos (Joseph, 1992). Como a psicoterapia psicanalítica promove uma aproximação mais genuína ao mundo interno, na busca da integração do self, as defesas desse tipo de paciente são um considerável desafio para a obtenção das mudanças psíquicas (Villela, 2006). A identificação das forças que atuam no sentido de dificultar a integração psíquica é uma diretriz do tratamento psicanalítico desses casos (Zimerman, 1988), comumente referidos na literatura psicanalítica como desvitalizados, desobjetalizados, de difícil acesso (Lamanno-Adamo, 2010).

Considerando os pressupostos apresentados, este artigo tem por objetivo analisar algumas vivências transferenciais de uma paciente de 29 anos durante seu atendimento psicoterápico em um serviço-escola de Psicologia. Pretende-se contribuir para o debate a respeito do manejo da transferência no processo terapêutico, particularmente em casos considerados de difícil acesso.

\section{Método}

O presente estudo debruça-se sobre um caso clínico seguido em contexto de clínica-escola, destacado como proposta de estudo de caso por sua relevância clínica e implicações terapêuticas. Propomos investigar as vicissitudes do vínculo transferencial em paciente de difícil acesso. Para tanto, utilizou-se como estratégia metodológica o estudo de caso individual (Peres \& Santos, 2005) e o enfoque psicanalítico para análise dos dados (Franke \& Silva, 2012), tomando em consideração que o método de interpretação na clínica psicanalítica não pode engessar a experiência clínica em valores universalizantes (Almeida \& Atallah, 2009). Para a seleção do caso clínico foram seguidas as recomendações preconizadas por Alt e Nunes (2007).

Atualmente, é reconhecida a relevância dos delineamentos de caso único no estudo do processo terapêutico, porém é cada vez mais discutida a necessidade de se definirem estratégias para aumentar a fidedignidade e validade dos estudos de caso, utilizadas na geração de pesquisa empírica em psicoterapia e psicanálise (Serralta, Nunes, \& Eizirik, 2001). A estratégia utilizada para incrementar a fidedignidade e validade do presente estudo de caso compreende a elaboração de um registro minucioso, sessão 
por sessão, do atendimento psicoterapêutico realizado com a paciente, complementado pela elaboração de narrativas que sumarizavam as supervisões que se seguiram às sessões terapêuticas realizadas.

Em relação ao referencial teórico escolhido, neste estudo, toma-se a psicanálise como método de investigação do inconsciente, a partir da qual se fundamenta um tratamento embasado em uma ética da escuta ao discurso, que manifesta o desejo de um sujeito (Franke \& Silva, 2012). Como notam esses autores, há um compromisso direto com a pessoa que busca livrar-se dos constrangimentos e entraves que obstaculizam seu desenvolvimento. Por outro lado, o psicanalista está inserido em uma comunidade de profissionais que também têm uma responsabilidade para com a produção de conhecimento e evolução teórica e técnica da psicanálise.

Mezan (1998) problematiza o exercício da escrita do caso clínico para o psicanalista preocupado em pensar e trabalhar, por meio desse recurso, as questões caras à clínica. Propõe uma nova concepção do valor clínico da escrita, que vai muito além da formulação racional de ideias, pois entende que a escrita permite ao autor renovar a experiência de dialogar consigo próprio.

\section{Participante}

Beatriz (nome fictício), 29 anos, é solteira, estudante universitária e mora com os pais. Informações mais detalhadas serão fornecidas na seção Resultados e Discussão.

\section{Procedimento}

Coleta de dados. Foram tomados os devidos cuidados éticos implicados neste tipo de estudo, relativos ao consentimento da participante e à garantia do direito ao anonimato, sigilo e confidencialidade dos dados. Todos os dados pessoais da paciente foram salvaguardados, assim como as questões éticas inerentes ao processo terapêutico. Com esse propósito, algumas informações foram omitidas ou mascaradas na descrição do caso clínico.
Os encontros foram realizados individualmente, em uma sala de atendimento psicológico de um serviço-escola de Psicologia. Os nomes próprios mencionados são fictícios e algumas informações veiculadas neste estudo foram alteradas, de modo a evitar a identificação da paciente e a preservar o sigilo dos dados.

A elaboração do corpus de pesquisa foi guiada pela intenção de destacar as vivências transferenciais da jovem paciente, que se encontrava em atendimento psicoterápico de orientação psicanalítica (Busch, 2010). O registro das sessões foi realizado pelo terapeuta logo após o seu término. Os relatos clínicos foram registrados na íntegra e literalmente, em forma de discurso direto, e submetidos pelo terapeuta à supervisão semanal, oferecida por um docente com especialização em psicoterapia psicanalítica. Ao término de cada supervisão clínica, o terapeuta redigia uma síntese dos achados elaborados naquele encontro, sob a forma de narrativa, que incluía seus próprios apontamentos, percepções e sentimentos despertados pelo contato com o material clínico em interlocução com o supervisor. Os registros das sessões e as narrativas elaboradas após as supervisões compuseram o corpus da pesquisa.

Análise dos dados. A interpretação do material clínico foi realizada concomitantemente à obtenção dos dados, isto é, ao longo do processo terapêutico em sessões semanais de supervisão, nas quais o pesquisador era supervisionado por um psicoterapeuta experiente, professor com livre-docência em psicoterapia psicanalítica. As interpretações basearam-se nas pautas de análise preconizadas pela literatura psicanalítica (Franke \& Silva, 2012; Serralta, Nunes, \& Eizirik, 2001), atentando-se para a questão da complexidade da posição assumida pelo pesquisador na pesquisa em psicoterapia psicanalítica (Borsa \& Nunes, 2008).

O material coligido ao longo do processo terapêutico foi submetido à análise de conteúdo (Bogdan \& Biklen, 1994), o que possibilitou examinar de forma pormenorizada 
os movimentos transferenciais. Os dados foram organizados levando-se em conta os núcleos de sentido - ou seja, a regularidade das respostas e os padrões convergentes de conteúdo. Para melhor inteligibilidade do material, optou-se por apresentar os Resultados articulados à Discussão, após uma breve contextualização do caso clínico (apresentação da paciente).

\section{Resultados e Discussão}

Pelo vértice das manifestações transferenciais, focalizaremos as experiências emocionais e os recursos psíquicos de que a dupla terapeuta-paciente pôde lançar mão para dar consistência à relação terapêutica. No decorrer do relato clínico, descrevemos os caminhos partilhados pela dupla em busca da manutenção do vínculo até sua iminente ruptura, na tentativa de recompor a experiência analítica por meio da escrita da trama transferencial (Andrade \& Santos, 2009; Rosa \& Santos, 2011).

\section{Apresentação da paciente}

Beatriz esteve sob atendimento psicoterápico individual, de orientação psicanalítica, conduzido em um serviço-escola de Psicologia, por aproximadamente nove meses. Os encontros terapêuticos tinham frequência de duas sessões semanais e totalizaram 48 sessões. As sessões duravam 50 minutos e ocorriam em situação face a face.

A paciente apresentava boa capacidade de reflexão e evidenciava inteligência acima da média. Frequentou regularmente o serviço até a segunda metade do segundo semestre, quando passou a ausentar-se de forma recorrente, tendo o cuidado de avisar o terapeuta quando não poderia comparecer. Em geral, justificava suas ausências alegando acúmulo de trabalhos e outros compromissos, como provas escolares.

$\mathrm{Na}$ entrevista inicial, a paciente queixouse da qualidade do relacionamento que mantinha com sua supervisora de estágio, classificando-a como intransigente. No curso do atendimento, estendeu essa queixa para outras pessoas, como seu namorado, sua mãe, sua irmã, amigas e parentes. Durante as sessões, relatou ter um relacionamento afetivo e caloroso com sua mãe, apresentando-a como uma figura provedora de cuidado e afeto; ao mesmo tempo, essa imagem de dedicação parecia ser rompida por fantasias de retaliação. Sentia sua irmã como uma pessoa impositiva, sobretudo em relação a ela, sugerindo um relacionamento marcado por ambivalência, já que esta, ao mesmo tempo em que a incentivava, punia seus investimentos internos e externos em direção ao seu amadurecimento pessoal.

\section{Evolução do caso}

O início do vínculo terapêutico foi marcado por manifestações persecutórias da paciente, manifestadas sob a forma de receio de que o terapeuta pudesse controlá-la, na medida em que a relação terapêutica colocava-a em contato com seus próprios sentimentos. Essas vivências a levaram a adotar manobras de evitação e recuo no movimento de aproximação à realidade interna. Por outro lado, em certas situações, apesar da considerável desorganização de seu mundo interno, Beatriz sentia-se claramente satisfeita em encontrar o terapeuta. Nas primeiras sessões e no decorrer das demais, a paciente evidenciou sentir-se extremamente desorganizada e confusa, conseguindo suportar a duras penas a ansiedade decorrente dessas manifestações. As vivências de insatisfação eram recorrentes e associadas a momentos de desorganização interna. Em várias ocasiões, Beatriz revelou-se perplexa e assustada frente ao contato com seu mundo interno, relatando ter receios de que espíritos a perseguissem. Em momentos de intensa angústia, parecia não alcançar uma convivência satisfatória com seus pensamentos e sentimentos, como se estivesse a ponto de fragmentar-se totalmente. Em outras situações, frente à considerável intensidade de sofrimento psíquico, essa confusão interna era substituída por aquilo que ela denominava de "branco", um vazio de pensamentos que algumas vezes a assaltava e que também ocorria quando sua supervisora dava-Ihe "broncas", momentos em que se sentia impotente. 
Essas situações de "vazio" também eram reproduzidas com frequência na psicoterapia, incrementando vivências de ansiedade. À medida que o tempo da sessão decorria, com o auxílio da continência do terapeuta, a paciente acalmava-se e aparentava recuperar um senso mínimo de integração psíquica. Esse movimento aplacatório pode sugerir que, para Beatriz, era muito importante perceber a condição do terapeuta de estar com ela, disponível e contenedor, em uma posição acolhedora e não-intrusiva, tentando suportar as angústias suscitadas pelo contato com seus "vazios" e "brancos" que o setting terapêutico estimulava. Podemos entender esses "vazios" e "brancos" como expressões de certas dimensões do psiquismo que não puderam ser suficientemente desenvolvidas, a ponto de adquirirem representação simbólica. Esses fenômenos evocavam aquilo que Zimerman (1999) denominou de buracos psíquicos, ou seja, aspectos do aparelho psíquico que não puderam ser amadurecidos e transformados devido à ausência de capacidade de continência (revèrie) da figura de apoio - geralmente, a figura materna. Essas lacunas do desenvolvimento emocional, deixadas por aquilo que não se pôde completar, estariam na raiz das "patologias do vazio" que povoam a clínica contemporânea.

Para Palhares (2008), o fenômeno transferencial promove o contato do paciente com suas emoções, ao mesmo tempo em que o analista também se sensibiliza diante dessas manifestações. De acordo com Mello Neto (2012), o paciente constrói um projeto transferencial, no qual o psicoterapeuta tem designado um lugar; se este se recusa a participar desse projeto, a psicoterapia não se inicia. Desse modo, trata-se de um encontro intersubjetivo, visto que ambos veem-se tomados reciprocamente por manifestações inconscientes, afetos e vivências, em um devir intra e interpsíquico. O tratamento analítico recupera o tempo morto do vazio inercial e do empobrecimento psíquico, que se manifestam nas reações hostis, defensivas do paciente, ao mesmo tempo em que convivem com manifestações de afeto positivo, "um duplo tempo não linear começa a ser vivido pelo par analista-analisando. Não é uma crônica dos acontecimentos que vai ser empreendida, mas a vivência do acontecimento passado será atualizada, fundindo-se com o tempo analítico" (p.101).

No curso da psicoterapia, frente à continência afetiva do terapeuta, a paciente, aos poucos, foi capaz de controlar melhor os assomos de angústia e retomar o fio associativo. Todavia, essa maior aproximação emocional com o terapeuta muitas vezes era sentida como fonte de ameaça. Por isso, ao recuperar sua capacidade de associar ideias, o vínculo era fortemente atacado por defesas paranoides. Por exemplo, em uma das sessões iniciais o terapeuta indagou se Beatriz gostaria de colocar sua cadeira mais próxima à poltrona dele, visto que lhe parecia que estavam por demais distantes. Ela respondeu que não, que daquela maneira "estava bom", o que parecia traduzir uma posição de reserva e cautela, um recuo frente à possibilidade de contato mais íntimo com seus sentimentos e, também, em termos da transferência, frente à proximidade física e psíquica com o terapeuta. Em situações como essa, Beatriz sentia-se exposta e vulnerável, como se tivesse baixado exageradamente a guarda, a ponto de se sentir com poucas defesas, correndo o risco de ser controlada ou subjugada pelo objeto persecutório que era projetado no terapeuta.

Em outros momentos, era o próprio terapeuta que se mostrava ansioso, perseguido por pensamentos de que não conseguiria atender satisfatoriamente a paciente, de que não seria capaz de ajudá-la a suprir suas necessidades emocionais. Por diversas vezes, percebeu-se com ódio de Beatriz, sobretudo quando ela faltava seguidamente ou quando racionalizava ou negava as interpretações relativas à transferência, talvez por sentir-se invadida pelo conteúdo apresentado por ele. Essas reações contratransferenciais culminaram no impacto desagradável ocorrido em determinada sessão, em que o terapeuta se deu conta de que estava sentindo um forte cheiro de tabaco emanado pela paciente, o que o levou a ter desejo de afastar-se dela, de modo análogo ao que ela também fazia em algumas situações. 
Em outra sessão, o impacto produzido pelo encontro da dupla, que por vezes parecia ser sentido como desagradável para ambos, culminou na queixa de vertigem da paciente, que afirmou ter sentido "tontura" assim que se sentou na poltrona da sala de atendimento. Pareceu haver, nesse instante, uma forte comunicação de inconsciente para inconsciente. A vertigem representaria uma tentativa da paciente de defender-se do que era vivenciado como potencial desagregação de seu mundo interno, já comentada anteriormente. Nessa situação, o terapeuta tentou tranquilizá-la, tomando a iniciativa de arejar o ambiente, ao aumentar a extensão da abertura das janelas e ligar o ventilador, demonstrando estar atento às suas manifestações. Todavia, não explorou com a paciente a experiência emocional intensa vivida pela dupla naquele momento. A atitude de holding foi eminentemente física, limitou-se a um nível de comunicação sensorial de acolhimento, perdendo-se a oportunidade de explorar as potencialidades da situação - indagar, por exemplo, a que ela atribuía sua falsa percepção de movimento - a vertigem deflagrada ao encontrar-se com ele. $\mathrm{O}$ decurso dessa sessão, em certos momentos, foi permeado por conversas amenas, como se a dupla tentasse esquecer-se do que incomodava a ambos ou aliviar-se da tensão suscitada pelo choque do encontro emocional, que parecia levar ao desfalecimento do vigor criativo.

No que tange ao contato da dupla, Freud (1912/1996b) afirma que o analista deve imiscuir-se em seu próprio inconsciente de maneira que possa tornar-se permeável e abrir-se ao inconsciente do outro. Para tal, não pode permitir que resistências que se manifestam em si próprio ocultem a identificação do material inconsciente, o que levaria à introdução de uma nova seleção no corpo da análise, pautando-se no princípio de que o paciente abriu mão de objeções lógicas e afetivas que poderiam levá-lo a selecionar suas associações. O autor ainda aponta que a análise pessoal do terapeuta é fundamental para que esse processo de sensibilização ao inconsciente do outro se efetive de maneira favorável ao curso da análise, a fim de que não projete na figura do paciente, dimensões que lhe são intrínsecas.
Em uma leitura kleiniana, os acontecimentos descritos anteriormente se aproximam teoricamente das proposições de Segal (1982), que afirma que o paciente projeta "para dentro" do analista suas figuras internas, afetando-o, o que leva à admissão de que a transferência está assentada em situações primitivas pré-verbais. As situações pré-verbais, em que o paciente "atua sobre a mente do analista", podem estar relacionadas a outras formas de comunicação primárias, dando-Ihes ressonância afetiva, ou podem ser predominantemente expressadas, significando ataques à comunicação, que, no entanto, quando compreendidas de forma apropriada, transformam-se em experiências comunicativas de fato.

Se olharmos desta maneira para a transferência, então se torna bastante claro que o que Freud descreve como atenção livremente flutuante se refere não apenas à abertura intelectual da mente, mas também a uma abertura especial dos sentimentos - permitir que nossos sentimentos, nossa mente sejam afetados pelo paciente em um grau muito mais elevado do que nós permitimos sermos afetados nas relações sociais normais (Segal, 1982, p. 119).

Segundo Segal (1982), a contratransferência é fonte importante para obtenção de informações sobre o paciente, além de ser elemento fundamental da interação paciente-analista. A maior parte dos processos transferenciais e contratransferenciais é de origem inconsciente. Quando a contratransferência do analista encontra-se afinada ao paciente, tem-se uma relação dupla, que contém e compreende ao mesmo tempo, que interpreta e produz conhecimento, dando origem ao fenômeno intitulado "intuição psicanalítica" ou "sentir-se em contato". Todavia, há situações em que esse fenômeno se rompe. $\mathrm{O}$ terapeuta pode tomar consciência de seus processos analíticos, na tentativa de pensar o que tais sentimentos evocam em sua relação com o paciente. A atitude de atenção flutuante envolve a capacidade de sustentar essa demanda paradoxal na dinâmica do vínculo transferencial. Cabe notar que qualquer comunicação envolve desejo de ação, de produzir efeitos na mente do outro, no entanto, a intensidade com que isso ocorre, 
sejam situações verbais ou não-verbais, varia de paciente para paciente e de momento para momento, intensificando-se conforme se aproximam dos processos psicóticos.

Para Ogden (1979), os processos contratransferenciais constituem um conjunto de fantasias e relações objetais correlacionadas, que, por serem indesejáveis, levam o self a depositá-las em outra pessoa, para então, recuperar o que foi projetado em versão modificada. Em trabalho posterior, que atesta o desenvolvimento desse conceito em sua obra, Ogden (1996) toma-o em sua qualidade intersubjetiva, na medida em que transforma a subjetividade daquele que projetou e do outro (recipiente):

[...] assim sendo, a identificação projetiva é um processo pelo qual a subjetividade, tanto do projetor quanto do recipiente, está sendo negada de diferentes maneiras: o projetor está recusando um aspecto de si próprio que ele imagina estar sendo evacuado para dentro do recipiente, ao passo que o recipiente está participando de uma negação de si próprio ao se render (criar espaço para) ao aspecto da subjetividade do projetor (Ogden, 1996, p. 96).

Não obstante essas manobras defensivas, em outras situações, o impacto emocional despertado pelo encontro da dupla parecia ser menos violento, embora permanecesse intenso e vigoroso. A paciente logo no início da sessão evidenciava estar satisfeita e abria um sorriso tímido, o que, transferencialmente, poderia significar que se regozijava por poder estar com o terapeuta, apesar da confusão presente em seu mundo interno e das fantasias persecutórias estarem sempre à espreita. Notava-se, nesses momentos de maior harmonia da dupla, que ela conseguia aproveitar-se do novo espaço de confiança e cuidado que a terapia instaurava em sua vida.

Essa situação amistosa também podia se modificar no desenrolar da própria sessão, quando Beatriz relatava sua dificuldade em conciliar as mudanças exigidas em sua vida e em seu cotidiano. Do ponto de vista transferencial, é possível hipotetizar que a possibilidade de manter contato com o terapeuta, de ser ouvida em suas necessidades e também de ouvir o que ele tinha a lhe dizer, poderia desestabilizar seus padrões de pensamento e condutas estabelecidas, ou seja, aquilo que ela já tinha como definido e definitivo em sua vida. Isso produzia o intenso desconforto de sentir que parte de seu mundo interno estava desorganizado ou prestes a se quebrar. O que poderia explicar porque, em vários momentos, Beatriz parecia sentir-se incomodada pelas interpretações da situação transferencial. Em certos momentos, pedia ao terapeuta que dissesse quais condutas deveria tomar, com o claro intuito de que concentrasse sua atenção e fala no conteúdo manifesto da sessão. Segundo Green (1979/2004), "a palavra do analista é metáfora de ação" (p. 17), o que leva alguns pacientes a se frustrarem frente à interpretação do analista, pois esperam que ele situe sua fala no âmbito do manifesto, da ação em vez da reflexão, a fim de gratificar a pulsão.

Em geral, quando o terapeuta interpretava as manifestações transferenciais, a paciente negava o conteúdo interpretado ou fazia uso de racionalização, parecendo ter receio das consequências que o estreitamento do vínculo poderia acarretar. A potencial desintegração de seu mundo interno também pode ter contribuído para suas ausências ou atrasos recorrentes, como se o temor de um eventual colapso das defesas e, por consequência, o triunfo da desagregação e do caos psíquico, não permitissem que a paciente chegasse ao atendimento com pontualidade e assiduidade, de modo a desfrutar do encontro em plenitude. Green (1988) chama a atenção para o significado da ausência no contexto analítico. Ausência que não é o mesmo que falta, mas um estado de carência. Ausência que está "no lugar" de algo do psíquico que malogrou, por falhas de operação do processo de simbolização. Nesse sentido, é uma ausência "repleta", da mesma maneira que o silêncio pode, às vezes, ser bastante eloquente. De acordo com Green (1979/2004, p. 25): "o silêncio pode, de fato, ser repleto de palavras silenciosas, portadoras do sentido consciente e inconsciente: pode, igualmente, estar cheio 
de outras coisas além de palavras. Mas pode também ser o inaudível do nunca ouvido".

Nota-se que, frente a esses sentimentos penosos e inaudíveis, o consumo excessivo de cigarros possibilitava-lhe um sentimento de aparente coesão, de ser "preenchida" por algo, ainda que evanescente e fugaz, produzindo um alívio imediato que, momentaneamente, permitia-lhe esquecer de sua busca incessante - o movimento repetitivo e estereotipado em busca de integração. O odor forte que deixava impregnado na atmosfera da sala era uma maneira sutil de marcar sua presença, garantindo que seria notada mesmo na ausência, ao imprimir sua marca indelével no corpo e na mente do terapeuta. Cuidava, assim, de deixar suas pegadas na memória de seu cuidador, buscando assegurar de algum modo que não seria esquecida ou negligenciada.

Essa maneira própria de se fazer notada se revela, na transferência, como uma manobra inconsciente para se presentificar na mente do terapeuta, após dele se afastar. Com isso, a paciente busca suprir a necessidade de refazer um tempo que se desfez com a separação de suas figuras primárias, uma perda cuja restauração exige um trabalho árduo de recoIher os sentimentos e colocá-los no coração (re-cordar) uma outra vez. Para reparar a experiência afetiva perdida, precisará utilizar o lastro do investimento pulsional que dá origem às fundações do narcisismo, sendo o ego, nos primórdios, a simples projeção do corpo, como Freud (1923/1996) notou com propriedade.

Pode-se conjeturar que, por meio de uma marca corporal - o hálito de cigarro -, Beatriz comunica, de modo não-verbal, seu desejo de permanecer vinculada à figura de apoio, ao mesmo tempo em que esse desejo inconsciente se articula de uma maneira tal que parece ser bastante desagradável para o terapeuta, produzindo efeito aversivo. Pode-se depreender, a partir da reação de repulsa que ela desperta inconscientemente no terapeuta, que o sentimento de ser rejeitada pelo objeto é uma dimensão central das experiências de vazio reproduzidas no vínculo terapêutico.
O objeto é sentido como não-confiável e abandonador, uma espécie de "supervisora" negligente em sua função, que em vez de "orientar", invariavelmente dá "broncas", diante de quem Beatriz se sente como uma criança frágil, incapaz de se defender e expressar seu desapontamento. $\mathrm{O}$ vínculo torna-se, assim, intoxicante, perpetuando as experiências de desamparo e o sentimento de abandono. Por outro lado, a paciente não consegue se desvencilhar desse laço tantalizante, sente-se aprisionada justamente por negar sua dependência afetiva e sentir-se aturdida ao endereçar sua demanda amorosa ao terapeuta.

No decorrer das sessões, o relato queixoso em relação à supervisora ressurgiu em diversas ocasiões, com ênfase sobre sua conduta autoritária. No entanto, nos meses finais do atendimento, Beatriz passou a relatar que, nas situações em que se sentia criticada, estava conseguindo argumentar e expor seus motivos, sem cair em prantos ou "ter brancos", como era de hábito. Provavelmente isso decorreu de uma mudança intrapsíquica: a repressão maciça do ódio que sentia pôde ser abrandada, na medida em que conseguiu compreender a natureza de seus sentimentos e elaborar sua experiência emocional durante a terapia.

Na continuidade do processo terapêutico, a paciente, que até então havia se mantido assídua, começou a faltar sistematicamente às sessões, buscando, no plano concreto do comportamento, substancializar a ausência que não pôde ser simbolizada e inscrita como uma realidade psíquica. Quando essa ausência de simbolização tenta se inscrever de algum modo no contexto analítico, ainda que seja na concretude de uma passagem ao ato, abre-se a possibilidade de o analista operar nessa fenda. Para tanto, é preciso estar atento para não reeditar, na experiência de cuidar emocionalmente da paciente, certas experiências desastrosas que foram vivenciadas no passado. Por outro lado, a paciente precisava perceber que o terapeuta mantinha-se atento ao que estava sucedendo no vínculo transferencial. Ela parecia ter deslocado para sua relação com ele parte da 
impotência que sentira anteriormente frente à supervisora: agora era ali, com ele, que se sentia impedida de "conseguir argumentar e mostrar seus motivos", ou seja, seu ódio decorrente da frustração por não obter a gratificação esperada.

A conduta de distanciamento da paciente sugere a necessidade defensiva de reconquistar a distância, isto é, retomar o intervalo em relação ao objeto, para restaurar a integridade de seu self, que havia se plasmado em vivências de indiferenciação. A dinâmica que se estabelece entre intimidade e distanciamento instaura o movimento desejante, que precisa ser manejado adequadamente, de modo a fortalecer a confiabilidade do setting, que prenuncia a possibilidade do encontro emocional. A estabilização do setting analítico é um requisito crucial para a condução clínica desses casos. Na medida em que as vivências caóticas e primitivas são reeditadas na situação analítica, com segurança e confiabilidade, cria-se a possibilidade de uma experiência emocional corretiva, que poderá conduzir o conflito a um desfecho mais satisfatório.

\section{Considerações finais}

No presente estudo apresentamos o caso clínico de Beatriz para ilustrar um processo terapêutico no qual a paciente se mantém aprisionada a um sistema mental primitivo (Villela, 2006), marcado por movimentos de cisão e projeção dos conflitos psíquicos. Diante do material clínico exposto, atentamos para as proposições teóricas de Klein (1952/1991), que prefere tratar de "situações totais de transferência", haja vista que durante todo o relato analisado percebe-se um movimento intenso da paciente em atribuir à figura do terapeuta certas fantasias e representações que permeavam seu mundo interno e que haviam sido vivenciadas em seu passado remoto com as figuras parentais.

Durante a primeira etapa do atendimento, a paciente mostrou-se muito disponível para o trabalho terapêutico. Aceitou prontamente as sugestões de horários e frequência semanal, comparecendo às sessões com assiduidade e pontualidade durante os primeiros meses. Esse padrão foi se alterando, na medida em que a transferência que estabeleceu foi se mostrando, com o passar do tempo, mais idealizada do que positiva. A relação emocional da dupla suscitou diversos matizes de manifestações transferenciais e contratransferenciais, em uma ligação de inconsciente para inconsciente muitas vezes impossível de ser interpretada, por não emergir em nível consciente.

Por outro lado, deve-se atentar para recomendação de Winnicott (1975) de que o analista deve conduzir o tratamento da maneira como a mãe se introduz na relação com seu bebê, isto é, apresentando os objetos do ambiente aos poucos, para que ele não se sinta invadido em suas frágeis fronteiras e precocemente assolado pelas asperezas da vida. Assim, frente a potencial desorganização do mundo interno da paciente, as possibilidades interpretativas advindas da transferência devem ser manejadas com cautela e parcimônia pelo terapeuta, como uma mãe suficientemente boa frente ao seu bebê, para que não agudizem estados primitivos de fragmentação egoica. Caso contrário, corre-se o risco de intensificar manifestações de vulnerabilidade presentes em algumas situações da vida do paciente de difícil acesso. 
Referências
Almeida, L. P., \& Atallah, R. M. F. (2009). Clínica, a interpretação psicanalítica e o campo de experimentação. Psicologia em Estudo (Maringá), 14(1), 149-157.

Alt, M. S., \& Nunes, M. L. T. (2007). Por que um caso se transforma em caso clínico?. Revista da Sociedade de Psicologia do Rio Grande do Sul, 6, 55-63.

Andrade, T. F., \& Santos, M. A. (2009). A experiência corporal de um adolescente com transtorno alimentar. Revista Latinoamericana de Psicopatologia Fundamental, 12(3), 454-468.

Bogdan, R. C., \& Biklen, S. K. (1994). Investigação qualitativa em educação: Uma introdução à teoria e aos métodos (M. J. Alvarez, S. B. Santos, T. M. Batista, Trads.). Porto, Portugal: Ciência da Educação.

Borsa, J. C., \& Nunes, M. L. T. (2008). O sujeito/pesquisador na pesquisa em psicologia clínica. Psicologia Argumento, 26(52), 47-54.

Busch, F. (2010). Distinguishing psychoanalysis from psychotherapy. The International Journal of Psychoanalysis, 91(1), 23-34.

D'Avila Lourenço, L. C. (2005). Transferência e complexo de Édipo, na obra de Freud: Notas sobre os destinos da transferência. Psicologia: Reflexão e Crítica, 18(1), 143-149.

Franke, D., \& Silva, J. C. (2012). Da escuta à escrita: A construção do caso clínico em psicanálise. Psicanálise \& Barroco em Revista, 10(2), 42-61.

Freud, S. (1996). Fragmento da análise de um caso de histeria. In Edição standard das obras psicológicas completas de Sigmund Freud (J. Salomão, trad., Vol. 7, pp. 13-116). Rio de Janeiro, RJ: Imago. (Trabalho original publicado em 1905).

Freud, S. (1996a). A dinâmica da transferência. In Edição standard das obras psicológicas completas de Sigmund Freud (J. Salomão, trad., Vol. 12, pp. 107-119). Rio de Janeiro, RJ: Imago. (Trabalho original publicado em 1912).

Freud, S. (1996b). Recomendações aos médicos que exercem a Psicanálise. In Edição standard das obras psicológicas completas de Sigmund Freud (J. Salomão, trad., Vol. 12, pp. 121-133). Rio de Janeiro, RJ: Imago. (Trabalho original publicado em 1912).
Freud, S. (1996). Resistência e repressão. In Edição standard das obras psicológicas completas de Sigmund Freud (J. Salomão, trad., Vol. 16, pp. 293-308). Rio de Janeiro, RJ: Imago. (Trabalho original publicado em 1916-1917).

Freud, S. (1996). O ego e o id. In Edição standard das obras psicológicas completas de Sigmund Freud (J. Salomão, trad., Vol. 19, pp. 13-80). Rio de Janeiro, RJ: Imago. (Trabalho original publicado em 1923).

Freud, S. (1978) Esboço de psicanálise. In Os pensadores (pp. 193-246). São Paulo, SP: Abril Cultural. (Original publicado em 1938-1940).

Green, A. (1988). O analista, a simbolização e a ausência no contexto analítico. In A. Green, Sobre a loucura pessoal (pp. 36-49). Rio de Janeiro, RJ: Imago.

Green, A. (2004). O silêncio do psicanalista. Psychê, 8(14), 13-18. (Trabalho original publicado em 1979).

Joseph, B. (1992). O paciente de difícil acesso. In M. Feldman, \& E. B. Spillius (Eds.), Equilíbrio psíquico e mudança psíquica ( $B$. H. Mandelbaum, trad., pp. 85-96). Rio de Janeiro, RJ: Imago.

Klein, M. (1991). Sobre os critérios para o término de uma psicanálise. In M. Klein, Inveja e gratidão e outros trabalhos (B. H. Mandelbaum, trad., pp. 64-69). Rio de Janeiro, RJ: Imago. (Original publicado em 1950).

Klein, M. (1991). As origens da transferência. In M. Klein, Inveja e gratidão e outros trabalhos. Rio de Janeiro, RJ: Imago. (Original publicado em 1952).

Lamanno-Adamo, V. L. C. (2010). Clone: o inferno do si mesmo. Revista Brasileira de Psicanálise, 44(4), 85-94.

Laplanche, J., \& Pontalis, J.-B. (2001). Vocabulário da psicanálise (4a ed., P. Tamen, Trad.). São Paulo, SP: Martins Fontes.

Mello Neto, G. A. R. (2012). Psicanálise: A clínica e o projeto transferencial. Psicologia em Estudo (Maringá), 17(3), 499-505.

Mezan, R. (1998). Escrever a clínica. São Paulo, SP: Casa do Psicólogo. 
Ogden, T. H. (1979). On projective identification. International Journal of Psycho-Analysis, 60, 357-373.

Ogden, T. H. (1996). Os sujeitos da psicanálise (C. Berliner, Trad.). São Paulo, SP: Casa do Psicólogo.

Palhares, M. C. A. (2008). Transferência e contratransferência: A clínica viva. Revista Brasileira de Psicanálise, 42(1), 100-111.

Peres, R. S., \& Santos, M. A. (2005). Considerações gerais e orientações práticas acerca do emprego de estudos de caso na pesquisa científica em Psicologia. Interações: Estudos e Pesquisa em Psicologia, 10(20), 109-126.

Rosa, B. P., \& Santos, M. A. (2011). Comorbidade entre bulimia e transtorno de personalidade borderline: Implicações para o tratamento. Revista Latinoamericana de Psicopatologia Fundamental, 14(2), 268-282.

Safra, G. (2005). Curando com histórias: A inclusão dos pais na consulta terapêutica das crianças. São Paulo, SP: Sobornost.

Segal, H. (1982). Contratransferência. In H. Segal, A obra de Hanna Segal: Uma abordagem kleiniana à prática clínica (pp. 117-125). Rio de Janeiro, RJ: Imago.
Serralta, F. B., Nunes, M. L. T., \& Eizirik, C. L. (2001). Considerações metodológicas sobre o estudo de caso na pesquisa em psicoterapia. Estudos de Psicologia (Campinas), 28(4), 501-510.

Villela, E. M. B. (2006). Mudanças psíquicas: Vicissitudes no trabalho de psicoterapia psicanalítica. Mudanças: Psicologia da Saúde, 14(1), 42-55.

Winnicott, D. W. (1975). Objetos transicionais e fenômenos transicionais. In D. W. Winnicott, $O$ brincar e a realidade (J. O. A. Abreu \& V. Nobre, trad., pp. 13-44). Rio de Janeiro, RJ: Imago.

Winnicott, D. W. (1993). Variedades clínicas da transferência. In D. W. Winnicott, Textos selecionados: Da pediatria à psicanálise (4a ed., J. Russo, trad., pp. 483-489). Rio de Janeiro, RJ: Francisco Alves.

Zimerman, D. E. (1988). Manejo técnico do paciente de difícil acesso. Revista Brasileira de Psicanálise, 22(2), 297-318.

Zimerman, D. E. (1999) Fundamentos psicanalíticos - Teoria, técnica e clínica: Uma abordagem didática. Porto Alegre, RS: Artmed. 


\section{Eduardo Name Risk}

Doutorando pelo Programa de Pós-Graduação em Psicologia, Faculdade de Filosofia, Ciências e Letras de Ribeirão Preto, Universidade de São Paulo, Ribeirão Preto - SP. Brasil. Apoio financeiro: CAPES.

E-mail: eduardonrisk@gmail.com

\section{Manoel Antônio dos Santos}

Professor Associado 3 da Faculdade de Filosofia, Ciências e Letras de Ribeirão Preto, Universidade de São Paulo, Ribeirão Preto - SP. Brasil. Apoio financeiro: CNPq. E-mail: masantos@ffclrp.usp.br

Endereço para envio de correspondência:

Avenida Bandeirantes, 3900. Monte Alegre. CEP: 14040901. Ribeirão Preto - SP. Brasil.

Recebido: 12/06/2014, Aprovado: 03/11/2015. 